\title{
Influence of operational parameters on the start-up of a flocculation airlift bioreactor
}

\author{
M. Luísa Sousa ${ }^{\mathrm{a}, *}$, Manuel Mota $^{\mathrm{b}}$, José A. Teixeira $^{\mathrm{a}}$ \\ ${ }^{a}$ Universidade do Porto, Fac. Eng., Dep. Eng. Química, Rua dos Bragas, 4099 Porto Codex, Portugal \\ ${ }^{b}$ Universidade do Minho, Dep. Eng. Biológica, Largo do Paço, 4719 Braga Codex, Portugal
}

(Received 22 March 1993; accepted 10 July 1993)

\begin{abstract}
The evolution of the fermentation parameters of a flocculating Saccharomyces yeast strain started up in a continuousiy operated internal loop airlift bioreactor was compared at different aeration rates $(0.02$ and 0.1 v.v.m., where v.v.m. represents the volume of air per volume of fermenter per minute and has the units $\left.11^{-1} \mathrm{~min}^{-1}\right)$ and dilution rates $(0.1$ and $0.2 \mathrm{~h}^{-1}$ ). The floc size distributions obtained were found to be different. The operating parameters do not seem to affect the glucose consumption rates, but instead affect the stoichiometry of its conversion to either ethanol or biomass, suggesting a shift in the metabolic mechanisms as biomass builds up.

Oxygen availability was not uniform in the fermenter, according to the global volumetric mass transfer coefficients determined.

The subsequent results establish a strong influence of the dilution and aeration rates on the measured variables (glucose, ethanol and biomass concentrations) and the calculated kinetic parameters (specific rates of glucose consumption, ethanol production and biomass growth).
\end{abstract}

Key words: Airlift bioreactor; Diffusion; Flocculation; Floc size; Oxygen transfer; Yeast

\section{Introduction}

An increase in productivity while keeping the substrate conversion and product concentration maximal is one of the main goals in continuous fermentation. This can be accomplished by maintaining a high concentration of microorganisms in the fermenter.

Among the techniques developed to achieve a high cell density, flocculation bioreactors, which explore the sedimentation characteristics of flocculent microorganisms, present several advantages when considering design simplicity and energy costs [1-3].

However, the phenomenon of cell aggregation may cause a reduction in the specific reaction rates because the diffusion rates of nutrients or products

\footnotetext{
*Corresponding author.
}

inside cell flocs are self-limiting [4,5]. Cell aggregation is a mass-transfer-controlled process. This effect is increased whenever the floc size increases.

Van't Riet and Tramper [6] report the sensitivity of microbial flocs undergoing morphological changes due to the surrounding hydrodynamic forces. Mota and Teixeira [7] observed a reduction in Kluyveromyces marxianus floc size on increasing the shear forces in a continuously operated fermenter, as a result of increasing the recycling rate. It seems then that bioreactor hydrodynamics may be a factor determining floc size.

Low abrasion characteristics are often the reason for choosing airlift bioreactors in which both oxygen for cell consumption and energy for mixing are provided by the inlet air $[8,9]$. As a result the aeration rate is a parameter that controls the shear forces. 
In this work, ethanolic fermentations using a highly flocculent Saccharomyces cereviseae strain were conducted in an airlift bioreactor operating continuously. The non-aggressive hydrodynamics allowed for the formation of pellets of increasingly large size as the biomass accumulated. In order to clarify the interaction between the kinetics of fermentation and floc size, start-up of the culture was studied under different aeration and dilution rates.

\section{Experimental}

\section{Organism}

A flocculent yeast strain, Saccharomyces cerevisiae NRRL Y265, was used.

\section{Feed}

The medium was prepared with tap water and had the following composition: glucose, $130 \mathrm{~g}$ $\mathrm{I}^{-1} ; \quad\left(\mathrm{NH}_{4}\right)_{2} \mathrm{SO}_{4}, 2 \mathrm{~g} \mathrm{l}^{-1} ; \mathrm{KH}_{2} \mathrm{PO}_{4}, \quad 5 \mathrm{~g} \mathrm{I}^{-1}$; $\mathrm{MgSO}_{4} \cdot 7 \mathrm{H}_{2} \mathrm{O}, 0.4 \mathrm{~g} \mathrm{l}^{-1}$; yeast extract, $1 \mathrm{~g} \mathrm{l}^{-1}$.

The medium was autoclaved at $121^{\circ} \mathrm{C}$ for $30 \mathrm{~min}$.

\section{Bioreactor}

An airlift bioreactor of the concentric draft tube or internal loop type, constructed from Perspex, was used and is shown in Fig. 1. Filtered air at the two aeration rates studied $(0.02$ and 0.1 v.v.m., where v.v.m. represents the volume of air per volume of fermenter per minute and has the units $11^{-1} \mathrm{~min}^{-1}$ ) is injected immediately below the annulus of the riser, thus promoting an ejection effect responsible for circulation inside the reactor. At the top, the inverted conic enlargement provides a degassing area and floc deceleration zone. Part of the fermented liquid sheers off naturally and the remainder is recirculated along with biomass into the downcomer and again into the riser. The working volume is 5.41 and the riser-downcomer diameter ratio is 0.4 . Fresh medium was fed at the bottom of the reactor at the two dilution rates

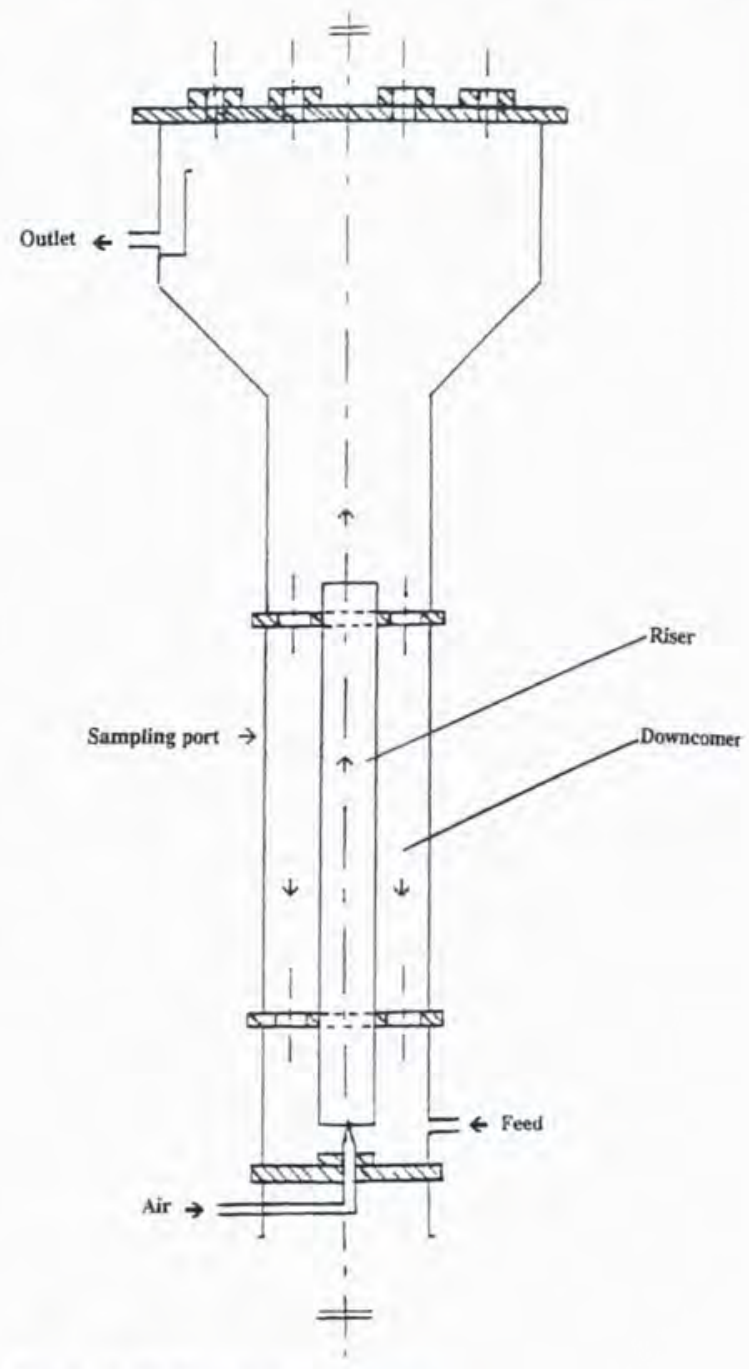

Fig. 1. Airlift flocculation bioreactor.

studied $\left(0.1\right.$ and $\left.0.2 \mathrm{~h}^{-1}\right)$. All experiments were carried out at $30^{\circ} \mathrm{C}$ and the $\mathrm{pH}$ was maintained at 4 by the automatic control of ammonia addition.

The mixing behaviour of the reactor was found, by a tracer method utilizing Methylene Blue [6]. to reproduce well that of an ideal continuous stirred tank reactor (CSTR) for all operating conditions.

The unit was sterilized chemically by filling it with a diluted pharmaceutical bactericide antimycotic detergent, removing all the air, then sealing off the reactor with autoclaved pieces and emptying 
it. The unit was washed with autoclaved water aseptically pumped inside the unit before the initial inoculation. The inoculum culture was grown in 51 Erlenmeyer flasks in the same medium and under the same conditions, with magnetic stirring for $48 \mathrm{~h}$.

\section{Start up}

Before each experiment the reactor was purged and then refilled with fresh medium in order to simulate the conditions following the initial inoculation: biomass concentration, about $4 \mathrm{~g} \mathrm{l}^{-1}$, residual ethanol concentration and glucose concentration similar to the initial ones. The initial floc size distribution is reproduced by maintaining strong aeration ( 0.2 v.v.m.) for about $1 \mathrm{~h}$, thus giving rise to flocs with an average size of $0.5 \mathrm{~mm}$. The desired dilution and aeration rates were then set and after $30 \mathrm{~min}, 20 \mathrm{ml}$ samples were removed periodically from inside the reactor and from the outlet, for biomass, glucose and ethanol analysis.

\section{Analysis}

The glucose concentration was determined by the dinitrosalicylic acid (DNS) method [10], and the ethanol concentration by gas chromatography with flame ionization detection using isopropanol as the internal standard [11]. The biomass concentration was determined by measuring the optical density at $620 \mathrm{~nm}$ of a suspension previously deflocculated by the addition of a solution of $15 \mathrm{~g}$ $\mathrm{I}^{-1}$ of $\mathrm{NaCl}$ at $\mathrm{pH} 2$ [12] and correlated to dry weight. For floc size distribution determinations, samples were collected on a Petri dish which was immediately placed on an amplifying photocopier. Millimetric paper was then overlaid on the contrast photocopy thus obtained, and floc dimensions were measured under a binocular lens according to a commonly used particle sizing technique [13]. For each sample, about 200 flocs were measured.

\section{Oxygen transfer}

The global volumetric mass transfer coefficients, $K_{1} a$, were determined by the dynamic method [14] using an Ingold polarimetric dissolved oxygen electrode. The electrode was placed in three different positions in the reactor (i.e. at the top of the riser, in the downcomer at a level $3 \mathrm{~cm}$ above the annulus of the riser, and at the degassing area) for each aeration rate studied, and for an air-water system, i.e. in the absence of a biochemical reaction.

Oxygen transfer rates were estimated from the steady state mass balance using the $K_{1} a$ values determined, the oxygen solubility in water and the steady state dissolved oxygen concentration observed for the particular fermentation.

The dynamic method with biochemical reaction [14] was used to determine the oxygen transfer rate in a batch fermenter with a low concentration of biomass and microscopic flocs of the same strain in a situation where the oxygen concentration in the liquid phase is close to the saturation value.

\section{Results and discussion}

Assuming that for such low concentrations of biomass as those in start up the reactor maintains the CSTR behaviour, the mass balances for biomass, glucose and ethanol lead to the following kinetic rate expressions:

$\mu_{\mathrm{X}}=1 / X\left(D X_{\mathrm{S}}+\mathrm{d} X / \mathrm{d} t\right)$

$q_{\mathrm{S}}=-1 / X\left(D\left(S-S_{0}\right)+\mathrm{d} S / \mathrm{d} t\right)$

$v_{\mathrm{p}}=1 / X(D P+\mathrm{d} P / \mathrm{d} t)$

where $\mu_{\mathrm{X}}$ is the biomass specific growth rate, $q_{\mathrm{S}}$ the glucose specific consumption rate, $v_{\mathrm{p}}$ the ethanol specific production rate, $D$ the dilution rate, $P$ the ethanol concentration in the reactor, $S$ the glucose concentration in the reactor, $S_{0}$ the glucose concentration in the feed, $X$ the biomass (dry weight) concentration in the reactor, $X_{\mathrm{S}}$ the biomass (dry weight) concentration in the effluent, and $t$ the time.

The variation of these rates during start up was 
calculated from the numerically smoothed experimental data.

Figure 2 shows these rates plotted against biomass concentration.

From Fig. 2 the following observations may be made.

(1) The highest specific biomass growth rates are observed for the start-up conditions of $D=$ $0.2 \mathrm{~h}^{-1}$, aeration rate $=0.1$ v.v.m; in all cases $\mu_{\mathrm{x}}$ decreases with biomass concentration.

(2) The highest specific ethanol production rates are observed for the start-up conditions of $D=$ $0.1 \mathrm{~h}^{-1}$, aeration rate $=0.02$ v.v.m.; for higher dilution rates or higher aeration rates, $v_{\mathrm{p}}$ is practically constant.

(3) The different start-up conditions do not seem to affect the specific glucose consumption rates, although in all cases it is significantly reduced when the biomass concentration reaches $6 \mathrm{~g} \mathrm{l}^{-1}$, and above that value $q_{\mathrm{s}}$ remains practically constant.

This leads to the conclusion that the studied parameters (dilution and aeration rates) do not seem to affect glucose consumption rates but instead do affect the stoichiometry of its conversion to either ethanol or biomass, suggesting a shift in the metabolic mechanism as biomass accumulates.

The changes in the stoichiometry of glucose conversion to ethanol are better expressed by another variable, the ethanol conversion yield, defined as

$\eta_{\mathrm{p}}=P /\left(S_{0}-S\right) / 0.5111$

Figure 3 presents these values versus biomass concentration.

The highest ethanol conversion yields are attained for $D=0.1 \mathrm{~h}^{-1}$ and an aeration rate of 0.02 v.v.m., and remain independent of the biomass concentration. For all the other start-up conditions, the yields increase with increasing biomass concentration up to a maximum, after which they remain constant. This confirms that during start up, changes in the overall reaction mechanisms occur, and that these changes are associated with the joint action of the dilution and aeration rates.
A similar shift in the metabolic activities of the same strain has been observed in situations where the mass transfer resistance inside the flocs is reduced [15].

It has been reported that the combined action of oxygen and substrate concentrations is responsible for changes in the metabolism of $S$. cerevisiae, indicating that below a certain value of glucose concentration, the availability of oxygen allows the yeast to respire or oxidize the glucose to water and $\mathrm{CO}_{2}$, yielding almost ten times more energy for cell growth than that resulting from a fermentative metabolism. The accumulation of metabolic products, ethanol and $\mathrm{CO}_{2}$, is also considered to be an inhibitory factor for cell growth [16].

Moreover, for larger floc sizes, diffusional limitations become more important, restricting the availability of nutrients, glucose and oxygen, and resulting in an accumulation of the metabolic products. Therefore some insight into the floc size evolution associated with oxygen transfer is required in order to explain the stated metabolic changes.

Soon after the inoculation, flocs with a featherlike structure give place to very small particles $(0.5 \mathrm{~mm})$ in the shape of flat ellipsoid discs. As fermentation proceeds, the particles maintain this shape but become increasingly large. On prolonging the fermentation further, the ellipsoid discs will develop a biconcave configuration and fragments of larger flocs will also be visible.

Figure 4 displays the relationship between floc size and biomass increase, better expressed by the average biomass content per floc, $m_{\mathrm{f}}$, calculated assuming a spherical geometry and constant floc density as follows:

$m_{\mathrm{f}}=\pi / 6 d_{\mathrm{f}}^{3} \rho_{\mathrm{f}}\left(1-\varepsilon_{\mathrm{f}}\right)$

where $d_{\mathrm{f}}$ is the weighted average floc dimension, $\rho_{\mathrm{f}}$ the floc specific gravity, and $\varepsilon_{\mathrm{f}}$ the floc porosity (mass of intercellular water per mass of floc).

The values of $\rho_{\mathrm{f}}$ and $\varepsilon_{\mathrm{f}}$ were considered to be those obtained for the same strain by Lima et al. [5], respectively $\rho_{\mathrm{f}}=1.1$ and $\varepsilon_{\mathrm{f}}=0.50$.

Clearly the average floc size is dependent on the 

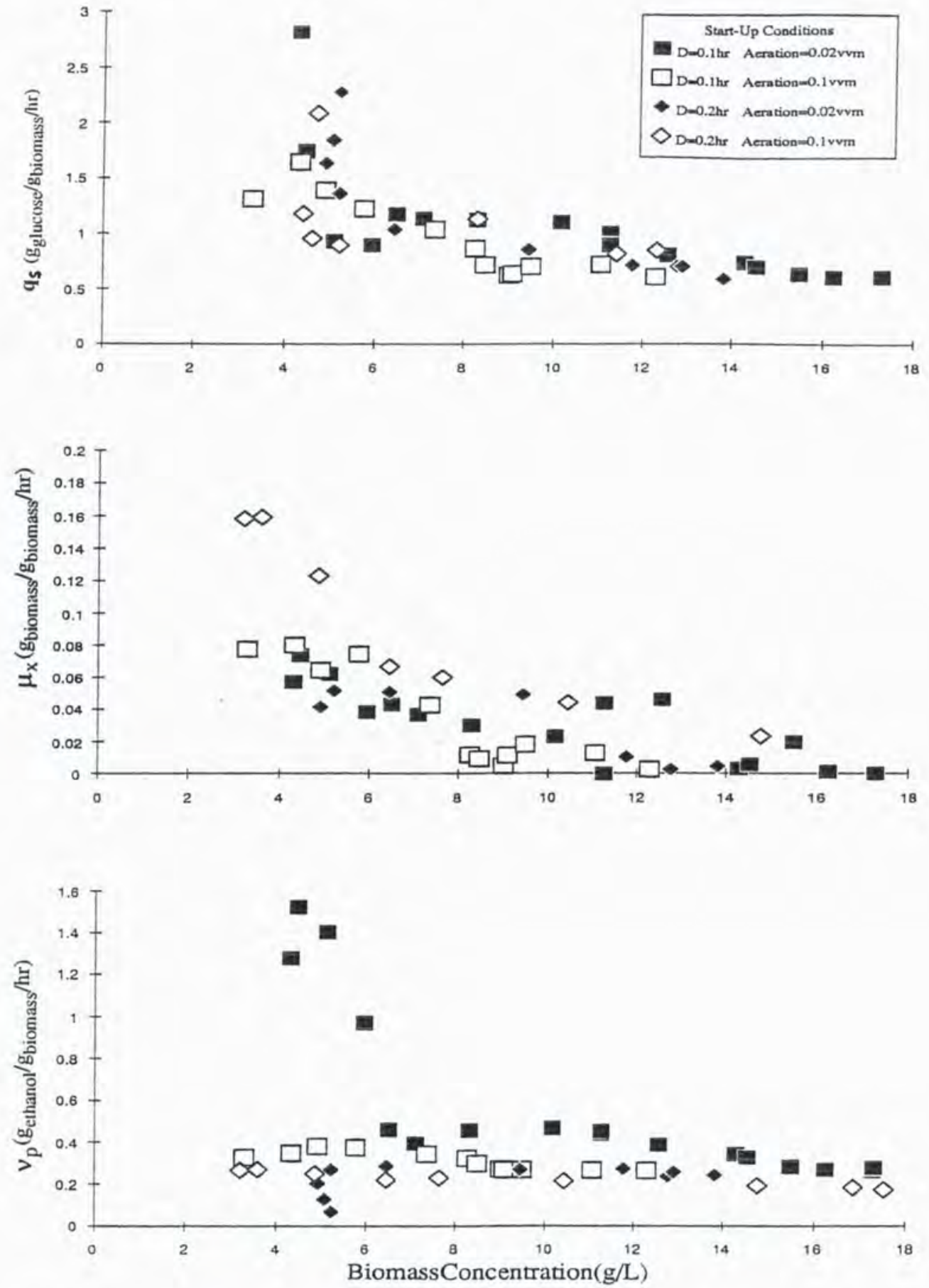

Fig. 2. Variation of the specific kinetic rates with biomass concentration for the four start-up conditions studied: $\mathbf{m}, D=0.1 \mathrm{~h}^{-1}$, aeration 0.02 v.v.m.; $\square, D=0.1 \mathrm{~h}^{-1}$, aeration 0.1 v.v.m.; $\bullet, D=0.2 \mathrm{~h}^{-1}$, aeration 0.02 v.v.m.; $\diamond, D=0.2 \mathrm{~h}^{-1}$, aeration 0.1 v.v.m. 


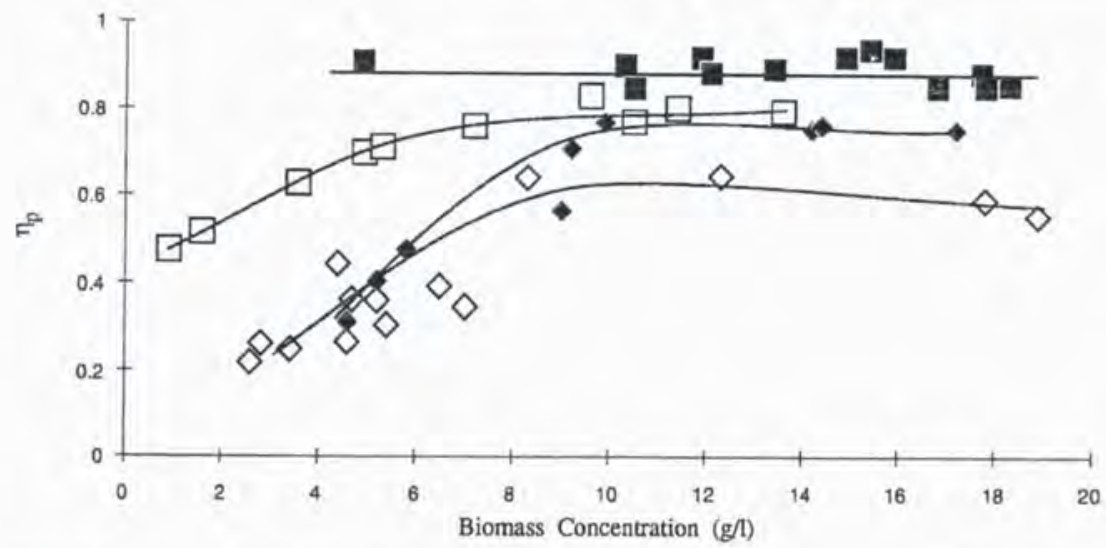

Fig. 3. Variation of ethanol conversion yields with biomass: $\mathbf{a}, D=0.1 \mathrm{~h}^{-1}$, aeration 0.02 v.v.m.; $\square, D=0.1 \mathrm{~h}^{-1}$, aeration 0.1 v.v.m.; - $D=0.2 \mathrm{~h}^{-1}$; aeration 0.02 v.v.m.; $\odot, D=0.2 \mathrm{~h}^{-1}$, aeration 0.1 v.v.m.

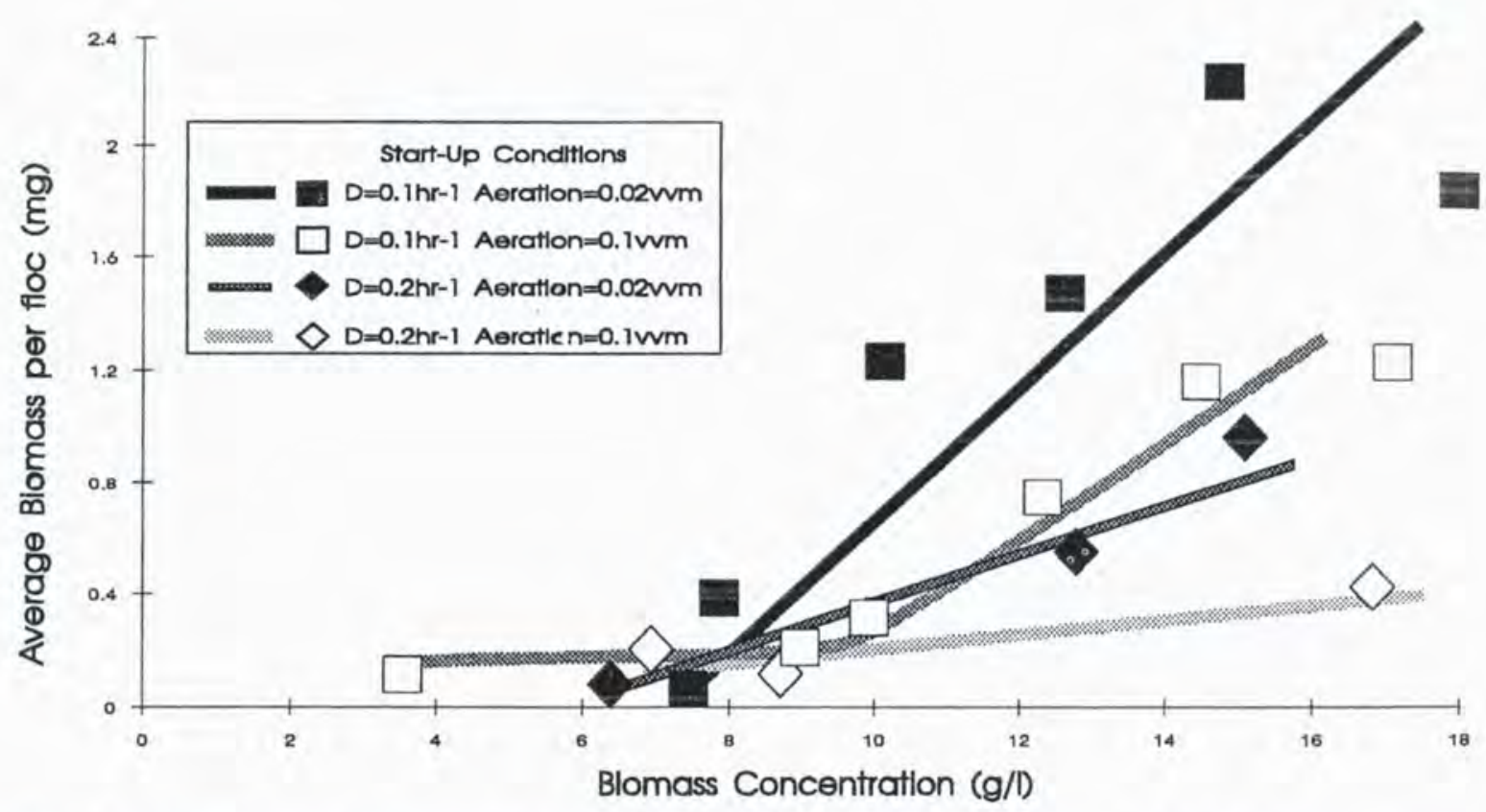

Fig. 4. Evolution of average biomass content per floc with biomass concentration in the reactor for the four start-up conditions.

aeration rather than on the kinetic rates, since for the same specific ethanol production rates (from Fig. 2) there may be different floc sizes.

Besides controlling the circulation velocities and, as a result, the shear forces to which the flocs are subjected, the aeration rate is directly related to the dissolved oxygen concentration in the reactor. For each biomass concentration it may be said that there is a steady state for the oxygen transfer and therefore all the oxygen transferred from the air bubbles to the liquid is consumed. This is expressed in the following equation:

$K_{1} a\left(C_{\mathrm{O}_{2}}^{*}-C_{\mathrm{O}_{2}}\right)=Q_{\mathrm{O}_{2}} X$

where $K_{1} a$ is the global volumetric mass transfer coefficient, $C_{\mathrm{O}_{2}}$ the steady state dissolved oxygen concentration, $C_{\mathrm{O}_{2}}^{*}$ the solubility of oxygen in the liquid, and $Q_{\mathrm{O}_{2}}$ the specific oxygen uptake rate. 
Having verified that the $K_{1} a$ values are poorly affected by the composition of the medium compared with water, and by neglecting the effect of such low biomass concentrations [17], the values determined in this work may be considered reasonable. No confirmation in the literature was found, since the available correlations refer to higher ranges of superficial gas velocity [17]. For the 0.02 v.v.m. aeration rate, the $K_{1} a$ value was $0.033 \mathrm{~min}^{-1}$ irrespective of the reactor zone, but for the 0.1 v.v.m. aeration rate $K_{1} a$ was significantly increased in the downcomer zone $\left(0.120 \mathrm{~min}^{-1}\right)$ compared with the riser $\left(0.100 \mathrm{~min}^{-1}\right)$ and the degassing zone $\left(0.085 \mathrm{~min}^{-1}\right)$. An explanation for the enhanced mass transfer in the downcomer zone is suggested by Lübbert et al. [18] to be a consequence of the fact that the difference between the gas and the liquid phase velocities is much greater in this zone, thus allowing a longer period of time to be available for the bubbles to transfer oxygen into the liquid. It is observed visually that bubbles formed by coalescence in this area tend to stand for a long period at the same level in the downcomer.

An average value of $K_{1} a$ was used for the calculations of the $Q_{\mathrm{O}_{2}}$ values which are presented in Table 1.

Assuming that the specific oxygen uptake rate determined experimentally for microscopic flocs $\left(Q_{\mathrm{O}_{2}}^{0}\right)$ is very close to that for the situation where no diffusional limitations to oxygen transfer arise, then an efficiency factor $E_{\mathrm{f}}$ could be calculated according to

$E_{\mathrm{f}}=Q_{\mathrm{O}_{2}} / Q_{\mathrm{O}_{2}}^{0}$

The oxygen uptake by yeasts follows zero-order kinetics [19]. Bailey and Ollis [20] demonstrate that, in this case, the relationship between the effectiveness factor and the critical diameter $d_{\mathrm{c}}$ for oxygen transfer is given by

$E_{\mathrm{f}}=1-\left(d_{\mathrm{c}} / d_{\mathrm{f}}\right)^{3}$

Hence the average depth $p_{\mathrm{d}}$ at which oxygen penetrates in the floc is

$p_{\mathrm{d}}=\left(d_{\mathrm{f}} / 2\right)\left[1-\left(1-E_{\mathrm{f}}\right)^{1 / 3}\right]$

The average percentage fraction of cells $f$, in the oxygenated outer shell is identical to the effectiveness factor:

$f=E_{\mathrm{f}} \times 100$

The calculated values of these parameters are presented in Table 1.

As expected, the oxygen uptake rates decrease with biomass and average floc size, and so does the effectiveness factor.

In fact, the estimated $E_{\mathrm{f}}$ values are very small, indicating that most of the cells (more than $74 \%$ ) in the reactor are deprived of oxygen. Yet, for the

Table 1

Experimental $K_{1} a$ values and estimated oxygen uptake rates, effectiveness factor $E_{\mathrm{f}}$, oxygen penetration depth $p_{\mathrm{d}}$ and fraction of cells, $f$, having oxygen available for given values of biomass concentration and aeration rate

\begin{tabular}{|c|c|c|c|c|c|c|c|c|}
\hline $\begin{array}{l}\text { Aeration } \\
\text { rate } \\
\text { (v.v.m.) }\end{array}$ & $\begin{array}{l}K_{1} a \\
\left(\min ^{-1}\right)\end{array}$ & $\begin{array}{l}X \\
\left(\mathrm{~g} \mathrm{I}^{-1}\right)\end{array}$ & $\begin{array}{l}d_{f} \\
(\mathrm{~mm})\end{array}$ & $\begin{array}{l}C_{\mathrm{O}_{2}} / C_{\mathrm{O}_{2}}^{* a} \\
(\%)\end{array}$ & $\begin{array}{l}Q_{\mathrm{O}_{2}}{ }^{\mathrm{b}} \\
\left(\mathrm{g}_{\mathrm{O}_{2}} \mathrm{~g}_{\text {biom }}{ }^{-1} \min ^{-1}\right)\end{array}$ & $E_{\mathrm{f}}$ & $\begin{array}{l}p_{\mathrm{d}} \\
(\mu \mathrm{m})\end{array}$ & $\begin{array}{l}f \\
(\%)\end{array}$ \\
\hline & & 18 & 1.9 & 1.8 & $7.0 \times 10^{-5}$ & 0.024 & 8 & 2.4 \\
\hline \multirow[t]{3}{*}{0.02} & 0.033 & 10 & 1.6 & 6.3 & $1.2 \times 10^{-4}$ & 0.041 & 11 & 4.1 \\
\hline & & 4 & 0.5 & 21.5 & $2.6 \times 10^{-4}$ & 0.089 & 8 & 8.9 \\
\hline & & 18 & 1.4 & 22.6 & $1.7 \times 10^{-4}$ & 0.059 & 14 & 5.9 \\
\hline \multirow[t]{2}{*}{0.1} & 0.102 & 10 & 0.9 & 41.0 & $2.4 \times 10^{-4}$ & 0.083 & 13 & 8.3 \\
\hline & & 4 & 0.5 & 54.1 & $4.7 \times 10^{-4}$ & 0.162 & 14 & 16.2 \\
\hline
\end{tabular}

${ }^{\mathrm{a}} \mathrm{C}_{\mathrm{O}_{2}}^{*}=0.0403 \mathrm{~g} \mathrm{l}^{-1}$ from Bailey and Ollis [20].

${ }^{b} Q_{O_{2}}^{\circ}=2.9 \times 10^{-3} \mathrm{~g}_{\mathrm{O}_{2}} \mathrm{~g}_{\text {biom }}{ }^{-1} \min ^{-1}$. 
same start-up stage, the highest aeration rate always enables a larger fraction of cells to respire.

As previously stated, $K_{1} a$ is not uniform for the 0.1 v.v.m. aeration rate, which means that the fraction of cells that contact with oxygen in the experiments will be greater mainly on the downcomer section. This is additional confirmation of the possible shift in metabolic activities.

\section{Conclusions}

Figure 5 outlines the effects of the aeration rate previously discussed.

In a flocculation bioreactor of the airlift type, it is the joint contribution of the dilution rate and the aeration rate that determines the start-up evolution, unlike conventional flocculation bioreactors and other high cell density systems for which this depends mainly on the dilution rate [1].

The oxygen supply is not uniform in this internal-loop airlift bioreactor and shows a higher value in the downcomer zone.

These factors influence the metabolic activities, controlling directly the substrate and oxygen supplies and indirectly the floc size and the predominance of either fermentative or respiratory mechanisms.

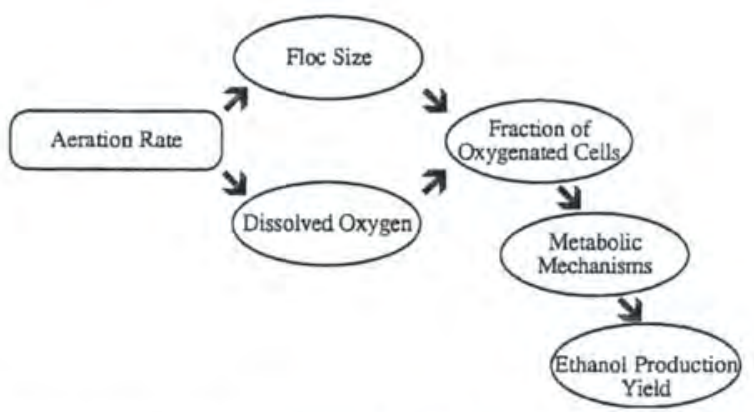

Fig. 5. Effects of the aeration rate in an airlift flocculation bioreactor.

\section{Acknowledgement}

This work was supported by J.N.I.C.T. (Junta Nacional de Investigação Cientifica e Tecnologica).

\section{References}

1 J.A. Teixeira, M. Mota and G. Goma, Bioprocess Eng., 5 (1990) 123-127.

2 C.B. Netto, A. Destruhart and G. Goma, Biotechnol. Lett., 7 (1985) 335-360.

3 J.P. Delgenes, R. Molleta and J.M. Navarro, Biotechnol. Lett., 10 (1988) 725-730.

4 J.A. Teixeira and M. Mota. Chem. Eng. J., 43 (1990) B13-B17.

5 N. Lima, J.A. Teixeira and M. Mota, Bioprocess Eng., 7 (1992) 343-348.

6 K. van't Riet and H. Tramper, Basic Bioreactor Design, Marcel Dekker, New York, 1991.

7 M. Mota and J.A. Teixeira, Chem. Biochem. Eng. Q. 5(1-2) (1991) 63-65.

8 F. Kargi and T.D. Cervoni, Biotechnol. Lett., 5(1) (1983) 33.

9 J. Kloosterman and M.D. Lilly, Biotechnol, Lett., 7(1) (1985) 25.

10 M.F. Chaplin and J.F. Kennedy, Carbohydrate Analysis: a Practical Approach, IRL Press, Oxford, 1986.

11 M. Mota, Thesis, Institute National des Sciences Appliquées, Toulouse, 1984.

12 C.B. Netto, Thesis, Institute National des Sciences Appliquées, Toulouse, 1984.

13 T. Allen, Particle Size Measurement, Chapman and Hall, London, 1974.

14 A. Moser, Bioprocess Technology: Kinetics and Reactors, Springer-Verlag, New York, 1988.

15 M.L. Sousa and J.A. Teixeira, Biotechnol. Lett., 13 (1991) 883-888.

16 H.J. Phaff, M.W. Miller and E.M. Mrak. The Life of Yeasts, Harvard University Press, Cambridge, MA, 1978.

17 M.Y. Chisti, Airlift Bioreactors, Elsevier, New York, 1989.

18 A. Lübbert, S. Fröhlich, B. Larson and K. Shügerl, in R. King (Ed.), Bioreactor Fluid Dynamics, Elsevier, Cambridge, 1988, pp. 379-393.

19 H.N. Chang and M. Moo-Young, Appl. Microbiol. Biotechnol., 29 (1988) 107-112.

20 J.E. Bailey and D.F. Ollis, Biochemical Engineering Fundamentals, McGraw-Hill, New York, 1986. 